\title{
Android and Forking Restrictions: On the Hidden Closedness of "Open”*
}

\author{
Simonetta Vezzoso ${ }^{* *}$
}

\begin{abstract}
The Google Android Decision was announced by the European Commission on 18 July 2018. The Commission found that three restrictions related to Android and Android apps that Google imposed on mobile device manufacturers and network operators infringed Article 102 TFEU. These restrictions, according to the Commission, "have enabled Google to use Android as a vehicle to cement the dominance of its search engine".

The Android Decision is not yet public. The prohibition of Google's tying practices on the Android platform has already attracted significant attention by early commentators, also due to the proximity to other high profile antitrust cases. Against the backdrop of the still limited information available, the article proposes some first reflections on another conduct sanctioned by the Android Decision, namely Google's forking restriction imposed on device manufacturers. In particular, the article describes a possible reasoning underpinning Google's anti-fragmentation justification based on the economics of two-sided platforms. This justification stems from a purely "transactional view" of platforms. The article concludes that this view is only partially suitable to provide an accurate description of complex innovation ecosystems for the purposes of competition policy enforcement.
\end{abstract}

KEYWORDS: abuse of dominance, software platform, forking, tying, platform.

\footnotetext{
* Date of reception: 26 July 2018. Date of acceptance: 30 July 2018.

** Simonetta Vezzoso is a Professor for Competition Policy and Intellectual Property and Senior Researcher at the Department of Economics and Management at the University of Trento, 38122 Trento, Italy, simonetta.vezzoso@unitn.it.
} 


\section{Introduction}

With the launch of their powerful smartphones in 2007 and 2008 respectively, Apple and Google started a revolution with wide-ranging consequences. ${ }^{1}$ One recent example is mobile payments, which are already driving parts of the world into a cashless society. ${ }^{2}$ The other defining element of the current digital transformation is the role played by data as fuel to an increasing number of services and products. When Google envisioned an add-based business model for its search engine, it transformed consumer data into one of the Internet's critical resources. Recent advances in computer science such as artificial intelligence and machine learning confirm the economic and societal relevance of data.

The Google Android Decision ${ }^{3}$ announced by the European Commission on 18 July 2018 ("the Android Decision" or "the Decision" hereinafter) is at the crossroad of these two developments. From Google's point of view, the operating system developed in house by Andy Rubin after the 2005 acquisition of its company was essentially a powerful tool aimed at funneling valuable consumer data into its own advertising machine. Perhaps understandably, there were also significant concerns that Microsoft could have ended up monopolising mobile the way it had done with the desktop, and heavily promoting its own search engine. ${ }^{4}$ At the time of Android's acquisition by Google, the handset ecosystem was still controlled to a substantial extent by wireless carriers, while Symbian (Nokia) and Microsoft were intensively focusing on proprietary solutions for the mobile-wireless sector. Google's intent in developing Android was also to build a platform that would "be free and clear of other licensing restrictions that were slowing

\footnotetext{
${ }^{1}$ Fred Vogelstein, Dogfight: How Apple and Google Went to War and Started a Revolution (New York: Harper Collins Publishers, 2013).

${ }^{2}$ Yuan Yang, "Why millennials are driving cashless revolution in China", Financial Times, July 17, 2018, https://www.ft.com/content/539e39b8-851b-11e8-a29d-73e3d454535d.

${ }^{3}$ European Commission, "Antitrust: Commission fines Google $€ 4.34$ billion for illegal practices regarding Android mobile devices to strengthen dominance of Google's search engine", EC Press Release, July 18, 2018, http://europa.eu/rapid/press-release_IP-18-4581_en.htm.

${ }^{4}$ Vogelstein, Dogfight, 51 ("Google executives were convinced that if Windows on mobile devices caught on, Microsoft would interfere with users' access to Google search on those devices in favour of its own search engine. The government's successful antitrust trial against Microsoft in the 1990s made it difficult for the company to use its monopoly on desktops and laptops to bully competitors... However, on smartphones, few rules governed how fiercely Microsoft could compete. It didn't have a monopoly there. Google worried that if Microsoft made it hard enough to use Google search on its mobile devices and easy enough to use Microsoft search, many users would just switch search engines").
} 
down others in the industry". ${ }^{5}$ Today, about $80 \%$ of smart mobile devices worldwide run on Android. While obviously not objecting to Android's launch and growth, the European Commission considers that some of the tactics employed by Google to expand its search engine's desktop success into the mobile environment were anticompetitive. Moreover, according to the European Commission, "Google's practices also harmed competition and further innovation in the wider mobile space, beyond just internet search". ${ }^{6}$ Consequently, the Mountain View company was fined $€ 4.3$ billion.

The Android investigation is one of three Google cases before the European Commission Competition Directorate since the beginning of this decade. The EU competition authority already found against Google in the shopping search case in $2017,{ }^{7}$ and is still considering further steps in the Google AdSense investigation. ${ }^{8}$

One of the interesting elements of the Android Decision is that it assesses strategies around open source from a competition policy perspective. The anticompetitive implications of free goods have already been widely debated in the antitrust literature. ${ }^{9}$ Openness, and open source in particular, are not new to antitrust enforcement either. ${ }^{10}$ The Decision is particularly relevant because it points to possible hidden restrictions and anticompetitive practices with regard to the software and contractual

\footnotetext{
${ }^{5}$ Transcript of Eric Schmidt's testimony at the Oracle v. Google trial, http://www.groklaw.net/ articlebasic.php?story=20120424115304346. At the time of Android's acquisition by Google, the handset ecosystem was still controlled to a large extent by wireless carriers, while Symbian (Nokia) and Microsoft were intensively focusing on proprietary solutions for the mobile-wireless sector.

${ }^{6}$ Android EC Press Release, supra note 3.

${ }^{7}$ Commission Decision of 27 June 2017, relating to proceedings under Article 102 of the Treaty on the Functioning of the European Union and Article 54 of the Agreement on the European Economic Area - CASE AT.39740 Google Search (Shopping), http://ec.europa.eu/competition/ antitrust/cases/dec_docs/39740/39740_14996_3.pdf.

${ }^{8}$ European Commission, "Commission takes further steps in investigations alleging Google's comparison shopping and advertising-related practices breach EU rules", EC Press Release, July 14, 2016, http://europa.eu/rapid/press-release_IP-16-2532_en.htm.

${ }^{9}$ See Michal S. Gal and Daniel L. Rubinfeld, "The hidden costs of free goods: Implications for antitrust enforcement", Antitrust Law Journal 80, no.401 (2016); John M. Newman, "Antitrust in zero-price markets: Foundations”, University of Pennsylvania Law Review, 164 (2015): 149.

${ }^{10}$ See Stephen M. Maurer, "The Penguin and the cartel: Rethinking antitrust and innovation policy for the age of commercial open source", Utah Law Review 1 (2012): 269-318; Simonetta Vezzoso, "Open source and merger policy - Insights from the European Commission's Oracle/Sun Decision”, International Review of Intellectual and Competition Law 1 (2011): 344-361.
} 
layers of open digital platforms, with potential relevance beyond the area of smart mobile phones.

The Android Decision is not yet public. The prohibition of Google's tying practices on the Android platform has already attracted significant attention by early commentators, ${ }^{11}$ also due to the proximity to other highprofile antitrust cases. Against the backdrop of the still limited information available, the article proposes some first reflections on another part of the Android Decision, namely the European Commission's assessment that Google's forking restrictions imposed on device manufacturers were in breach of Article 102 TFEU.

\section{The Android ecosystem}

Android is a software platform designed specifically ${ }^{12}$ for mobile broadband devices. ${ }^{13}$ A platform is a layered architecture of digital technology combined with a governance model. ${ }^{14}$ The Android platform includes an operating system which consists of Linux (Torvald's kernel), a middleware layer, and an application framework. The middleware layer of Android's architecture includes libraries, i.e. available implementations of common functionality that an application can readily tap into, and a virtual machine, i.e. a virtual computer running on top of the operating system with the function of executing user applications written in Java byte code,

\footnotetext{
${ }^{11}$ See Pinar Akmar, "Will the European Commission's Google Android Decision benefit consumers?", Truth on the Market, July 19, 2018, https://truthonthemarket.com/2018/07/19/will-theeuropean-commissions-google-android-decision-benefit-consumers/amp; Randy Picker, "The European Commission picks a fight with Google Android over business models", Pro Market, July 23, 2018, https://promarket.org/european-commission-picks-fight-google-android-businessmodels/; Stephen Houck, "Android - Is there a viable monopolization case?", August 1, 2018, https://papers.ssrn.com/sol3/papers.cfm?abstract_id=3230355. Alexandre de Cornière and Greg Taylor, "On the economics of the Google Android case", Vox, August 15, 2018, https://voxeu.org/ article/economics-google-android-case. At least one commentator, however, considers that also the forking ban deserves significant attention, see Pablo Ibanez Colomo, "The Android decision is out: the exciting legal stuff beneath the noise”, Chilling Competition, July 18, 2018, https://chillingcompetition.com/2018/07/18/the-android-decision-is-out-the-exciting-legal-stuff-beneath-thenoise-by-pablo/amp/.

${ }^{12}$ See Open Handset Alliance, "Overview", http://www.openhandsetalliance.com/oha_overview. html ("Android was built from the ground up with the explicit goal to be the first open, complete, and free platform created specifically for mobile devices").

${ }^{13}$ Mobile broadband devices are computing devices with wireless Internet access made for portability, namely smartphones, tablets, smartwatches, and other wearable computers.

${ }^{14}$ See Geoffrey G. Parker, Marshall W. Van Alstyne, and Sangeet P. Choudary, Platform Revolution (New York: W.W. Norton \& Company, 2016).
} 
a specific type of instructions Java software is compiled to. Android's application framework consists of the programs that manage the smart mobile device's basic functions like resource manager, telephone applications, etc. At the top of the "software stack" are Google's applications such as Google Play, Google Search, Gmail, Google Calendar, YouTube, Google Earth, etc. Wikipedia lists a total of 167 apps developed by Google for Android, ${ }^{15}$ and there are currently more than 2.8 million Android apps in the market. ${ }^{16}$

Android is managed in the context of the Open Handset Alliance (OHA), a dedicated industry consortium formed by heterogeneous players, namely wireless service providers, makers of mobile devices, chipset manufacturers, software companies, and commercialisation companies. The OHA currently comprises 86 members, such as T-Mobile, Telefónica, Huawei, Samsung, ZTE, Intel, eBay, Accenture, etc. ${ }^{17}$ Google plays the role of the leader or orchestrator within the consortium. ${ }^{18}$ The first Android mobile device was unveiled in September $2008^{19}$ and by November 2017 there were 2.3 billion of Android devices in use..$^{20}$ Google as the sponsor of the Android platform enforces platform rules through a combination of compatibility provisions, contracts, and trademark licences.

The Android Open Source Project (AOSP) coordinates the development of the platform. Under the AOSP, the Android code is open and free of charge. ${ }^{21}$ While device manufacturers can freely use the code under the

\footnotetext{
${ }^{15}$ See "List of Google apps for Android", Wikipedia, http://en.wikipedia.org/wiki/List_of_Google_ apps_for_Android.

${ }^{16}$ According to AppBrain, see http://www.appbrain.com/stats/number-of-android-apps.

${ }^{17}$ See Open Handset Alliance, https://www.openhandsetalliance.com/oha_members.html. The members promote the Android platform in various ways, in particular sharing intellectual property rights.

${ }^{18}$ Annabelle Gawer and Michael A. Cusumano, "Platform Leadership", Harvard Business School Press, June 24, 2002, https://hbswk.hbs.edu/archive/platform-leadership-how-intel-microsoftand-cisco-drive-industry-innovation-do-you-have-platform-leadership.

${ }^{19}$ The HTC Dream, also known as the T-Mobile G1, featured a slide-out QWERTY keyboard, 3G support, Wi-Fi, GPS, and Bluetooth. Google developed the first Android device together with the device maker HTC and the wireless carrier T-Mobile. Both HTC and T-Mobile had already helped Andy Rubin build the then highly considered mobile device Sidekick when he still ran the company Danger, see Vogelstein, Dogfight, 50 and 63 ("Danger, the company that made the Sidekick, got its name from what the robot in the 1960s TV show Lost in Space barked whenever it sensed, well, danger").

${ }^{20}$ See Bernd van der Wielen, "Insights into the 2.3 billion Android smartphones in use around the world", Newzoo, January 17, 2018, https://newzoo.com/insights/articles/insights-into-the-2-3billion-android-smartphones-in-use-around-the-world/.

${ }^{21}$ Hence, free as in free beer.
} 
AOSP, they need a certificate from an authorised testing facility and, arguably, Google's final written approval ${ }^{22}$ if they want to use a suite of proprietary apps known as Android's Google Mobile Services (GMS). GMS includes a variety of Google apps, such as Google Maps, YouTube, Google Play, and Google Search. The Android Compatibility Program requires handset manufacturers to comply with certain specifications and contract terms. Every Android release has its own Compatibility Definition Document (CDD) ${ }^{23}$ and Compliance Test Suite (CTS). The CDD specifies the requirements that must be met for a device to be considered compatible. It covers all aspects of the device's hardware and software capabilities. For instance, the device must be able to install and run.apk files. ${ }^{24} \mathrm{With}$ regard to hardware compatibility, there are specifications concerning display, graphics, input devices, sensors, data connectivity, cameras, memory storage, etc.

A manufacturer opting to preload the GMS suite, and therefore licensing Google's proprietary mobile apps, enters into a Mobile Applications Distribution Agreement (MADA) with Google. The MADA is negotiated with each device manufacturer individually and on a device-by-device basis. The two MADAs that have become publicly available so far ${ }^{25}$ contain a set of obligations for handset manufacturers. Thus, for instance, the manufacturer must set Google Phone-top Search as the default search provider for all web search points on the device. It means that Google Search is invoked by default if an app uses the search functionality. Furthermore, if the manufacturer chooses to preload the GMS suite on a device, it must preload the complete GMS suite (i.e., no "cherry-picking" allowed). The

\footnotetext{
${ }^{22}$ See Motorola's and Samsung's contracts with Google, whose exact language was extensively debated during the Skyhook court proceedings, see Skyhook Wireless, Inc. vs. Google Inc., 86 Mass. App. Ct. 611, No. 13-P-1236, https://cases.justia.com/massachusetts/court-of-appeals/201413-p-1236.pdf?ts=1415286156, at 8, Footnote 11 ('“'Google must provide terminal acceptance of a Device in writing before initial distribution of the Device in each individual Territory"; and "For the avoidance of doubt, each new Territory, each new Device, and each new Telecom Operator in each Territory needs to be approved by Google prior to Launch." Samsung's contract with Google includes similar language").

${ }^{23}$ The last version of the 132-page long CDD was published on 8 August 2018, available at https:// source.android.com/compatibility/9/android-9-cdd.pdf.

${ }^{24}$ All Android apps developing using the Android Standard Development Kit (SDK) are compiled into apk files.

${ }^{25}$ The MADAs between Google and HTC and Samsung respectively became publicly available during the already mentioned Oracle v. Google litigation, http://www.benedelman.org/docs/htcmada.pdf (HTC) and http://www.benedelman.org/docs/samsung-mada.pdf (Samsung).
} 
MADA also specifies the location of some GMS apps on the mobile device's screen, like the Google Search Widget and the Google Play icon. The terms of the two MADAs that are publicly available do not seem to impose any exclusive pre-installation requirements for Google Search, or other apps comprised in the GMS suite, on device manufacturers. ${ }^{26}$

Traditionally, every version of the Android platform has a corresponding version of the software development kit (SDK) exposing the same APIs to developers when they create their applications as will be present on hardware devices implementing that version of the platform. The compatibility guidelines and tests ensure that, for a device certified as compatible for a given version, the same APIs that developers are relying on for that version of the SDK are indeed implemented on the device and offer the same functionality specified to developers. In September 2012 Google introduced Google Play Services (GPS), a new app to the Play Store, which is supported on Android 2.2 and up. The GPS offers a set of core components and APIs that Google itself can update or replace no matter what version of Android the device is running. In this way, Google unbundled API development from official platform releases and sped up the development of its APIs. Moreover, this move made it more difficult for app developers to write apps for forked Android platforms. ${ }^{27}$

As mentioned above, the Android code under the AOSP is open, free of charge and available to anyone to download and modify. Anyone can freely use and develop the OS code under the AOSP to create a modified mobile operating system (a so-called "Android fork") and empower mobile devices with it. Devices running the code that comes under the AOSP do not have to meet any technical requirement specified by Google. However, if a handset manufacturer wishes to pre-install Google proprietary apps, as seen above, its devices must be considered "compatible", i.e. be compliant with the compatibility requirements, pass the compatibility test and receive Google's written approval, and they must also enter a MADA. Moreover, the handset manufacturer is also required to sign an

\footnotetext{
${ }^{26}$ Cf. Torsten Körber, "Let's talk about Android - Observations on competition in the field of mobile operating systems", Working Paper (2014), http://papers.ssrn.com/sol3/papers. cfm?abstract_id=2462393, 9 ("MADA are negotiated between Google and OEMs individually and on a device-by-device basis. Therefore, there might be versions of the MADA for certain devices that include exclusive pre-installation and default requirements").

${ }^{27}$ See Kimmo Karhu, Robin Gustafsson, and Kalle Lyytinen, "Exploiting and defending open digital platforms with boundary resources: Android's five platform forks", Information Systems Research 29, no. 2(2018): 479-487.
} 
"Anti-Fragmentation Agreement" (AFA). What the latter really states is, however, at this stage unclear since the text is confidential and has not been made available otherwise. ${ }^{28}$ Apparently, the AFA prohibits the device manufacturers from taking any actions that would fragment Android. In essence, this is a restriction on the device manufacturers' ability to market Android mobile smartphones that are considered compatible by Google and at the same time sell devices based on forks of the code under the AOSP that do not comply with the compatibility requirements set by Google. Instead, the device manufacturer is free to market non-Android devices, that is, devices based on other operating systems such as Tizen. An academic paper partially financed by Google, whose Author could have benefitted from some otherwise non-publicly available information, confirms that the AFA signatories promise "not to take any actions that may cause the fragmentation of Android". ${ }^{29}$

On the Android platform, Google earns most of its revenues from the mobile advertising side of the business, in particular mobile search advertising and in-app advertising. Employing a biological metaphor, the "advertisers' group" of the Android platform can be considered as "the 'plankton' that keeps the ecosystem alive and well". ${ }^{30}$

To a comparatively smaller extent, Google earns revenue from application providers who sell their apps to Android users and from directly selling entertainment (digital movies, music, etc.) and services to mobile users (e.g., Google Drive cloud storage). Moreover, and critically to Google's Android business model, Android devices collect valuable user data in an impressive number of active and passive ways, and, apparently, even in the absence of any user interaction. In fact, according to a recent report, a

\footnotetext{
${ }^{28}$ See Benjamin Edelman and Damien Geradin, "Android and competition law: Exploring and assessing Google's practices in mobile", European Competition Journal 12 (2016), 166 ("The provisions of the AFA are confidential, and as far as we know, no copy has ever been released to the public - not from Google, through litigation, by accident or in any other way. Nonetheless, Google confirms the existence of the AFA, explaining that "we ask manufacturers who are preloading our apps to put their device through a compatibility test and sign our Anti-Fragmentation Agreement" citation omitted).

${ }^{29}$ Cfr. Christopher S. Yoo, "Open source, modular platforms, and the challenge of fragmentation", University of Pennsylvania, Institute for Law \& Economic Research Paper no. 16-29 (2016), https:// papers.ssrn.com/sol3/papers.cfm?abstract_id=2866666.

${ }^{30}$ Slinger Jansen and Michael A. Cusumano, "Defining software ecosystems: a survey of software platforms and business network governance", in Software Ecosystems: Analyzing and Managing Business Networks in the Software Industry, ed. Slinger Jansen, Sjaak Brinkkemper and Michael Cusumano (Cheltenham: Edward Elgar Publishing, 2013), 14.
} 
"stationary Android phone (with Chrome active in the background) communicated location information to Google 340 times during a 24-hour period, or at an average of 14 data communications per hour... location information constituted $35 \%$ of all the data samples sent to Google". ${ }^{31}$

The comprehensive array of Google's mobile products and services route consumer data to advertising services. As stated by former Google's Senior Vice President for Mobile Andy Rubin, "We don't monetize the thing we create. We monetize the people that use it. The more people that use our products, the more opportunity we have to advertise to them". ${ }^{32}$

\section{The 2018 Android Infringement Decision (in a press release)}

The European Commission has been looking into the Android platform at least since 2013, when Fairsearch, ${ }^{33}$ an ICT industry coalition whose members at that time included Expedia, Microsoft ${ }^{34}$ and Oracle, filed a legal complaint claiming that Google was engaging in anticompetitive practices. Four other known complaints followed, by Aptoide, a Portugalbased independent Android app store, ${ }^{35}$ Disconnect, a Californian privacy and ad-blocking service, ${ }^{36}$ the Russian search engine Yandex, ${ }^{37}$ and the

\footnotetext{
${ }^{31}$ See Douglas Schmidt, “Google data collection”, Digital Content Next, August 2018, https://digitalcontentnext.org/wp-content/uploads/2018/08/DCN-Google-Data-Collection-Paper.pdf, 3. Google has, however, dismissed the Report's allegations in a statement: "[T]his report is commissioned by a professional DC lobbyist group, and written by a witness for Oracle in their ongoing copyright litigation with Google. So, it's no surprise that it contains wildly misleading information."

${ }^{32}$ See Steven Levy, In the Plex: How Google Thinks, Works, and Shapes Our Lives (New York: Simon and Schuster, 2011), 229.

${ }^{33}$ See FairSearch, "FairSearch announces complaint in EU on Google's anti-competitive mobile strategy", April 8, 2013, http://fairsearch.org/fairsearch-announces-complaint-in-eu-on-googles-anti-competitive-mobile-strategy/.

${ }^{34}$ Microsoft made known its intention to quit Fairsearch in December 2015, as revealed in Mark Bergen, "Microsoft quietly retreats from FairSearch, watchdog behind Google antitrust cases", Recode, January 22, 2016, https://www.recode.net/2016/1/22/11588992/microsoft-quietly-retreatsfrom-fairsearch-watchdog-behind-google.

${ }^{35}$ Cf. Paulo Trezentos, "Enough is enough: When Google evil reaches Android app stores", Aptoide, June 17, 2014, https://blog.aptoide.com/enough_is_enough_when_google_evil_reaches_ android_app_stores-2/ .

${ }^{36}$ See Complaint of Disconnect, Inc., "Regarding Google's infringement of Article 102 TFEU through bundling into the Android platform and the related exclusion of competing privacy and security technology - Case COMP/40099", June 2015, https:/www.documentcloud.org/ documents/2109044-disconnect-google-antitrust-complaint.html.

${ }^{37}$ See Maria Kiselyova, "Russia's Yandex says complained to EU over Google's Android”, Reuters, November 13, 2015, https://www.reuters.com/article/us-eu-antitrust-google-yandex-idUSKCN0T21L420151113.
} 
Open Internet Project, whose members include Axel Springer and Getty Images. ${ }^{38}$

In April 2015, the Commission initiated a formal proceeding against Google with the aim of determining whether Google had "illegally hindered the development and market access of rival mobile operating systems, mobile communication applications and services in the European Economic Area". ${ }^{39}$ The Commission suggested that Google might have done so by "requiring or incentivising smartphone and tablet manufacturers to exclusively pre-install Google's own applications or services", by "prevent[ing] smartphone and tablet manufacturers who wish to install Google's applications and services on some of their Android devices from developing and marketing modified and potentially competing versions of Android", and by "tying or bundling certain Google applications and services distributed on Android devices with other Google applications, services and/or application programming interfaces of Google". On 20 April 2016, the Commission sent a statement of objections to Google Inc. and its parent company Alphabet Inc. ${ }^{40}$ More than two years later, on 18 July 2018, Competition Commissioner Vestager announced a decision finding that three restrictions related to Android and Android apps that Google imposed on mobile device manufacturers and network operators Google infringed Article 102 TFEU. These restrictions, according to the Commission, "have enabled Google to use Android as a vehicle to cement the dominance of its search engine". ${ }^{11}$

The Decision establishes that Google holds a dominant position in three different markets: general search services, licensable smart mobile operating systems, and app stores for the Android mobile operating system. Henceforth, the European Commission considers that three of Google's practices are in breach of Article 102 TFEU.

First, the Decision addresses the tying of Google's search and browser apps with the Play Store. The Play Store gives users the possibility to download other apps on Android devices and, according to the Commission's findings, users expect to find it pre-installed on their devices (a "must-have"

\footnotetext{
${ }^{38}$ See Reuters, "Google foe takes Android complaint to EU regulators", Fortune, March 7, 2017, http://fortune.com/2017/03/07/google-antitrust-eu-android/.

${ }^{39}$ Cfr. European Commission, "Antitrust: Commission opens formal investigation against Google in relation to Android mobile operating system", EU Press Release, April 15, 2015, http://europa. eu/rapid/press-release_MEMO-15-4782_en.htm.

${ }^{40}$ European Commission, "Commission takes further steps".

${ }^{41}$ European Commission, "Antitrust: Commission fines Google”.
} 
app). Google Search and Google Chrome ${ }^{42}$ are "the most important gateways to reach search engines on mobile devices". By making the pre-installation of Google Search and Google Chrome as a condition for licensing the Play Store, Google has ensured that these apps are available on almost all Android devices sold in the EEA. Whereas users could easily download other search and browser apps on their devices, the Commission considers that the pre-installation "can create a status quo bias", as confirmed by evidence of concrete users' behaviour in a setting where Google Search and Chrome are not pre-installed. Thus, the Commission found that on Windows Mobile devices more than $75 \%$ of search queries happened on the pre-installed Microsoft's Bing search engine. Conversely, on Android devices with Google Search and Chrome pre-installed, more than 95\% of all search queries were made via Google Search. As Commissioner Vestager put it, "the evidence shows that when it comes to search apps and mobile browsers, the vast majority of users simply take what comes on their device and do not download competing apps". ${ }^{43}$ Moreover, the Commission came to the conclusion that the tying of the Google Search app and Chrome browser with the Google Play, and the related distribution advantage given to these apps, were not necessary to recoup Google's investment in Android. The tying restrictions ensure that users of Android devices resort to Google's search engines for their queries, thereby generating massive streams of revenue from search advertising. Without these restrictions, however, Google would still be able to monetise its investment in Android: first, the Google Play Store guarantees "billions of dollars in annual revenues"; second, Google collects vast troves of valuable users' data from Android devices; finally, even without the restrictions, many users would still use Google's search engine, thereby generating significant revenue streams.

The requirement to pre-install the Google Search and Chrome apps seen above does not comprise the device manufacturer's obligation to exclusively do so. Device manufacturers are therefore in principle free to pre-install competitors' search and browser apps. According to the Commission, the second contractual restriction in breach of Article 102 TFEU consists in

\footnotetext{
${ }^{42}$ Google Search is the default search engine on Google Chrome.

${ }^{43}$ European Commission, "Statement by Commissioner Vestager on Commission decision to fine Google €4.34 billion for illegal practices regarding Android mobile devices to strengthen dominance of Google's search engine", July 18, 2018, http://europa.eu/rapid/press-release_ STATEMENT-18-4584_en.htm.
} 
payments made to some of the largest device manufacturers as well as mobile network operators ${ }^{44}$ conditional on exclusive pre-installation of Google Search across their entire portfolio of Android devices.

The third restriction imposed by Google on device manufacturers considered abusive by the Commission relates to a slightly different set of strategies employed by Google. These specific practices aim at the obstruction of the development and distribution of competing Android operating systems, so called "Android forks". As seen in the previous Section, the AFA requires device manufacturers not to sell devices running versions of Android that Google considers "non-compatible". It follows from the complex contractual and technical framework that if manufacturers want to pre-install on their devices Google's proprietary apps, including the Play Store, they have to commit not to develop or sell even a single device running on an Android fork. Put differently, any device manufacturer that offered any model running any non-approved Android fork would lose its ability to include any Google apps on its phones. This also means that developers of Android forks face great difficulty finding device manufacturers that are willing to pre-install their operating system. This significantly reduces the viability of Android forks and therefore restricts what would otherwise be an alternative platform on which rivals provide apps and services that compete with Google's own apps and services. The Commission considers that this restriction of Android forks is abusive as of 2011, which is the date Google became dominant in the market for app stores for the Android mobile operating system.

Having found Google in breach of Article 102 TFEU, the company is required to pay a fine of $€ 4342865000$, as calculated on the basis of the value of Google's revenue from search advertising services on Android devices in the EEA. While the monetary fine imposed on Google is the highest in the enforcement history of the European Commission so far, it is unlikely to have much effect on the Mountain View company. "Based on the company's reported annual revenue of $\$ 110.9$ billion for the year", it was noticed that Alphabet, Google's parent company, "generated about the same amount of money every 16 days in 2017 " ${ }^{45}$ The record second-

\footnotetext{
${ }^{44}$ Mobile network operators can also determine what apps are installed on devices they sell to consumers.

${ }^{45}$ Aoife White, Stephanie Bodoni, and Natalia Drozdiak, "Google fined record $\$ 5$ billion by EU, given 90 days to stop 'illegal practices”, Bloomberg, July 18, 2018, https://www.bloomberg.com/ news/articles/2018-07-17/google-said-to-have-11th-hour-call-with-eu-ahead-of-android-fine.
} 
quarter results posted by Alphabet less than a week after the Decision was announced further contain the fine's likely impact on Google's financial prospects. ${ }^{46}$

Moreover, Google is required to bring its illegal conduct to an end in an effective manner within 90 days of the decision. At a minimum, Google must stop and not re-engage in any of the three types of practices considered abusive by the Commission. The decision also requires Google to refrain from any measure that has the same or an equivalent object or effect as these abusive practices. Overall, according to EU Competition Commissioner Margrethe Vestager, the decision "stops Google from controlling which search and browser apps manufacturers can pre-install on Android devices, or which Android operating system they can adopt" ${ }^{47}$ In a first reaction to the Decision, Google has already announced the intention to appeal it. ${ }^{48}$ Referring to the unbundling of the Play Store from the Search and the Chrome browser, Alphabet's CEO Sundar Pichai already suggested that the Decision would not significantly affect the Android strategy. He said that he was confident that a way would be found "to make sure Android is available at scale to users everywhere". ${ }^{49}$

There are well-grounded doubts that simply putting an end to the contested behaviours will produce the effect of restoring competition in the markets harmed by what the Commission considers serious abusive practices. ${ }^{50}$ Arguably, only very strong behavioural or even structural remedies could produce such effects. As to the former, it is first important to note that the experience gathered by the European Commission in the wake of the EU Microsoft cases could help inform appropriate assessment criteria regarding the effectiveness of the remedies that Google is going to

\footnotetext{
${ }^{46}$ Mark Bergen, "Alphabet soars to record after earnings wallop expectations", Bloomberg, July 24, 2018, https://www.bloomberg.com/news/articles/2018-07-24/alphabet-results-support-companyconfidence-in-face-of-eu-curbs ("Even including the record fine, the company generated $\$ 3.2$ billion in net income during the second quarter").

${ }^{47}$ European Commission, "Statement by Commissioner Vestager".

${ }^{48}$ Sundar Pichai, "Android has created more choice, not less", Google Blog, July 18, 2018, https:// www.blog.google/around-the-globe/google-europe/android-has-created-more-choice-not-less/.

${ }^{49}$ Mark Bergen, "Alphabet soars to record".

${ }^{50}$ Richard Waters, "Brussels takes aim at Google's mobile strategy", Financial Times, July 18, 2018, https://www.ft.com/content/8ddd8b86-8aa9-11e8-bf9e-8771d5404543 ("'Any action by the EU is akin to shutting the stable door after the horse has bolted', said Geoff Blaber, an analyst at CCS Insight").
} 
suggest. ${ }^{51}$ Second, it is not the first time that Google is forced by competition authorities to modify the governance of its Android mobile platform. In fact, in 2017 Google concluded a voluntary settlement with the Russian competition agency, the Federal Antimonopoly Service, following an investigation regarding concerns similar to the ones that form the object of the EU Android decision. As part of the settlement, Google could "no longer demand exclusivity of its applications on Android-based devices in Russia", and was obliged "not to restrict pre-installation of any competing search engines and applications (including on the default home screen)" and "to refrain from stimulating pre-installation of the Google search as the only general search engine". Moreover, Google committed to developing "an active 'choice window' (...) for the Chrome Browser which at the time of the next update will provide the user with the opportunity to choose their default search engine". ${ }^{52}$ The updated Chrome Browser was shipped in August 2017 and according the some estimates, by the end of September 2017 its impact was already visible in terms of a three percent points fall in Google's general search engine market share on Android devices. ${ }^{53}$

Google has 90 days to bring its illegal conduct to an end in an effective manner and the Commission has already indicated that it will strictly monitor Google's compliance with the Decision.

\section{Forking restriction as restrictive practice and its justification}

\subsection{A première under Article 102 TFEU}

It is the first time that the EU competition enforcer decides that a forking restriction imposed by a dominant undertaking is a stand-alone anticompetitive practice. In the Press Release accompanying the Decision's announcement, the Commission specifies that it "assessed in detail Google's arguments that these restrictions were necessary to prevent a

\footnotetext{
${ }^{51}$ See in particular Nicholas Economides and Ioannis Lianos, "A critical appraisal of remedies in the E.U. Microsoft cases", Columbia Business Law Review no. 2 (2010), 346.

${ }^{52}$ See Federal Antimonopoly Service of the Russian Federation, "FAS Russia reaches settlement with Google", FAS Press Release, April 17, 2017, http://en.fas.gov.ru/press-center/news/detail. html?id=49774.

${ }^{53}$ See Brenden McGonigle, "How the Russian search market looks now", Search Engine Land, September 25, 2017, https://searchengineland.com/how-russian-search-market-looks-283072/ amp.
} 
'fragmentation' of the Android ecosystem and concluded that these were not well founded". ${ }^{4}$

Technologists currently use terms like forking and fragmentation to describe the presence of competing standards. Forking is an example of horizontal incompatibility where one of the rival platforms (or standards) already has an installed base. ${ }^{55}$ In the case of a software platform like Android, "hard" fragmentation takes place when handset makers "fork" the operating system into alternative projects in order to differentiate their devices. "Soft" fragmentation occurs when the software platform owner decides to release new versions of the operating system, but hardware manufacturers (and wireless carriers) decide to not immediately upgrade to that version. Therefore, applications written for the most recent version of the operating system may not work with the older versions. This second form of fragmentation is common even among closely-controlled proprietary operating systems and devices, such as the Apple IOS. Thus, for instance, apps which run on one version of Apple IOS may not run on other versions of the same IOS.

If the broader contours of what is meant by fragmentation are sufficiently clear, there is no immediate consensus among technologists regarding its precise meaning in specific contexts. As noted by Tim Bray, a Google engineer working in 2010 on the Android platform, "nobody ever defined "fragmentation" - or rather, everybody has a different definition". Therefore, he adds, as fragmentation "means everything, it actually means nothing, so the term is useless" and, essentially, "is a bogeyman, a red herring, a story you tell to frighten junior developers". ${ }^{56}$

As seen above, the AFA agreement commits a device manufacturer who wishes to pre-install Google proprietary apps, including Google Play Store and Google Search, on any of its devices, not to sell devices running on Android forks. The term "fork" apparently entered computer science

\footnotetext{
${ }^{54}$ European Commission, "Antitrust: Commission fines Google".

${ }^{55}$ Cfr. Timothy Simcoe and Jeremy Watson, "Forking, fragmentation, and splintering", Working Paper - Boston University (2017).

${ }^{56}$ Tim Bray, “On Android compatibility”, Android Developers Blog, May 31, 2010, https://androiddevelopers.googleblog.com/2010/05/on-android-compatibility.html ("Some people use it to mean too many mobile operating systems; others to refer to optional APIs causing inconsistent platform implementations; still others use it to refer to "locked down" devices, or even to the existence of multiple versions of the software at the same time. I've even seen it used to refer to the existence of different UI skins. Most of these definitions don't even have any impact on whether apps can run!").
} 
already in 1962/1963. ${ }^{57}$ In very general terms, forking means "copying an existing program and distributing a modified version of it" ${ }^{58}$ Unix was the first computer program to be extensively forked. ${ }^{59}$

The open source literature proposes a distinction between competitive and non-competitive forks. The goal of the former is "to serve needs identical to those of the original program, often by producing a near-identical product to that from which it was forked" and "will by default compete with the original for its users and developers" ${ }^{60}$ While starting-off producing a product that is identical or very similar to the original, "over time the competitive fork may try to gain a competitive advantage through features or solutions that differ from the original". ${ }^{61}$ However, even a noncompetitive fork that is born out of a desire to "alter the direction of the development significantly" can end up affecting "the original as there may be those among both users and developers who switch to the fork". ${ }^{62}$

According to a recent study, the Android platform was already affected by five major competitive forking attempts. ${ }^{63}$ Among the five Android fork cases analysed, one originated from an OHA member, namely Acer. Google prevented Acer from launching the Aliyun phone, based on an Android fork, in partnership with Alibaba. Google justified the move stating that the "non-compatible versions of Android, like Aliyun, weaken the ecosystem. All members of the Open Handset Alliance have committed to building one Android platform and to not ship non-compatible Android devices" ${ }^{64}$ As noted by the Authors of the study, "[T]his situation... reveals hidden tensions within the OHA as to how far other members can "expand" the official Android platform and related resources without incurring a penalty" ${ }^{65}$ Put differently, according to Google, even a fork of

\footnotetext{
${ }^{57}$ See Linus Nyman, "Understanding code forking in open source software", Hanken School of Economics (2015), 26, http://s8.pdfconvertonline.com/convert/p3r68-cdx67/cppml-5oyg9.pdf.

${ }^{58}$ Nyman, "Understanding code forking", 1.

${ }^{59}$ Nyman, "Understanding code forking", 30. AT\&T used to distribute Unix freely upon request as the well-known 1956 consent decree with that Department of Justice forbade the company from engaging in any business other than telecommunications.

${ }^{60}$ Nyman, "Understanding code forking", 39.

${ }^{61}$ Nyman, "Understanding code forking", 40.

${ }^{62}$ Nyman, "Understanding code forking", 40.

${ }^{63}$ See Kahru, Gustafsson, and Lyytinen, "Exploiting and defending open digital platforms".

${ }^{64}$ See Danny Sullivan, "Google: Acer can't work on "non-compatible Android" \& be part of Open Handset Alliance”, Marketing Land, September 14, 2012, https://marketingland.com/google-acerandroid-aliyun-21631.

${ }^{65}$ Kahru, Gustafsson, and Lyytinen, "Exploiting and defending open digital platforms", 487.
} 
the Android operating system that is reputed outside of the Android ecosystem, could create compatibility issues that might justify its prohibition. After Google made clear that it intended "to terminate its Android-related cooperation and other technology licensing" ${ }^{\prime 66}$ if products running Aliyun OS were distributed, Acer abruptly cancelled its products' launch. ${ }^{67}$

Based on the publicly available information, little is known about how the Commission has been concretely assessing the forking restriction in the Android case. In the Press Release, the Commission makes it clear that the obstruction of development and distribution of competing Android operating systems amounts to an abuse of dominant position. The way in which Google restricted "the opportunity and incentive for others to develop Android forks", observes the Competition Commissioner Margrethe Vestager, was "not open at all", and "reduced the opportunity for rival search engines and others to launch apps and services on devices running on Android forks". ${ }^{68}$ Put it differently, the Commission considers abusive the contractual restriction that prevented device manufacturers with GMS-powered lines of products to experiment with the open source part of the Android OS in ways Google did not endorse (i.e., that Google considered "incompatible").

The concrete nature of the illegal conduct is not further discussed in the Press Release. It seems plausible, however, that the abuse the Commission condemns is of the exclusionary kind. The Commission refers to evidence of device manufacturers' foreclosure, in so far as Google's conduct prevented a number of them from developing and selling devices based on an Amazon's Android fork called "Fire OS". As Amazon tried to license its Android fork to device manufacturers and to "bring them on board", they declined because of Google's forking restriction. Despite its vast resources, content, etc., Amazon was unable to compete with Google's Android mobile platform. While the Amazon Fire phone is now defunct, the Fire OS lives on in other devices, such as Amazon's Fire Tablets and Echo devices. Moreover, there might be documentary evidence of Google's intent to use the forking restriction instrumentally. Thus, as Google's engineer wrote in

\footnotetext{
${ }^{66}$ Danny Sullivan, "Google: Acer can’t work on "non-compatible Android”.

${ }^{67}$ Jerry Hildenbrand, "Acer forced to halt device launch over Android compliance - here's why", Android Central, September 14, 2012, https:/www.androidcentral.com/acer-forced-halt-devicelaunch-over-android-compliance-here-s-why

${ }^{68}$ European Commission, "Statement by Commissioner Vestager".
} 
an internal mail: "we were using compatibility as a club to make [OEMs] do what we want". 69

In the Press Release, the Commission alleges that the fragmentation argument put forth by Google to justify the forking restriction has been duly ("in detail") assessed and dismissed. The Commission acknowledges that Google can legitimately require from manufacturers marketing Android devices using Google proprietary apps and services that fulfil specific technical requirements. This is reiterated in the part of the Press Release briefly discussing the remedy to Google's abuses of dominant position. Here the Commission asserts that the decision "does not prevent Google from putting in place a reasonable, fair and objective system to ensure the correct functioning of Android devices using Google proprietary apps and services, without however affecting device manufacturers' freedom to produce devices based on Android forks". Whereas the Commission is keen to underline that "(I)t is Google's sole responsibility to ensure compliance with the... decision", with regard to the appropriate remedy to the abusive forking restriction, the Commission expects the new system to be "reasonable, fair and objective", without preventing the emergence of Android forks. It is abundantly clear that the Commission views the establishment of such a system technically feasible and that this is one of the reasons underpinning the abusive nature of the forking restriction.

Moreover, the Commission was not convinced by the evidence that Google provided on the technical failures that would affect Android forks and that would therefore justify a strong ban on forking activities. The Commission does not explain what the technical failures alleged by Google were. Similarly, the Commission is only hinting at the unconvincing evidence that Android forks would fail to support apps.

It will be particularly interesting to read this part of the Decision, once published, also to understand the level of technical sophistication, the factual density in the exchange of arguments and counterarguments, and the legal and economic theoretical frameworks that played a decisive role in the Commission's final assessment of Google's practices. What is evident already is that Google's compatibility argument as justification for the forking ban imposed on handset manufacturers was unable to convince the competition agency for a whole array of reasons. This point is

${ }^{69}$ Nilay Patel, "How Google controls Android: digging deep into the Skyhook filings", The Verge, May 12, 2011, https://www.theverge.com/2011/05/12/google-android-skyhook-lawsuit-motorolasamsung. 
particularly relevant also considering that, as explained in the following Subsection, Google's argument could be supported by modern economic thinking, in particular by the theory of multisided businesses elaborated in the last years by industrial economists, whose influence is otherwise growing in antitrust circles, in the EU and beyond. ${ }^{70}$

\subsection{Fragmentation issues in light of the economics of multisided businesses}

We have seen above that handset manufacturers wishing to manufacture commercially-viable Android devices must not only sign the MADA but also the AFA, preventing them from selling devices running Android forks. While the European Commission views this as a breach of Article 102 TFEU, Google justifies the forking restriction by alleging that it is aimed at avoiding fragmentation issues. As we will explain in the following, Google's fragmentation argument could be much in line with recent economic thinking.

Arguably, Android as a software platform falls rather neatly into the category of multi-sided businesses. ${ }^{71}$ Generally, there are positive externalities between the different users' groups. The first side consists of users of Android mobile devices. The second side is made of application developers who write applications that work with the operating system and provide value to users and advertisers. ${ }^{72}$ The third group consists of device manufacturers. Device manufacturers sell more mobile devices if Android users have more apps that work with their products. The fourth side consists of advertisers who want to reach the mobile device users. Advertisers pay for the ability to present advertising messages to the users of Android mobile platform. ${ }^{73}$

With regard to the Android platform, Google earns revenues from the mobile advertising side of the business, in particular mobile search

\footnotetext{
${ }^{70}$ Dick Auer and Nicolas Petit, "Two-sided markets and the challenge of turning economic theory into antitrust policy", Antitrust Bulletin 60, no.4 (2015): 426-461.

${ }^{71}$ See J. Gregory Sidak, "Do free mobile apps harm consumers?", Working Paper (2014), http:// papers.ssrn.com/sol3/papers.cfm?abstract_id=2507905, 28.

${ }^{72}$ A similar category would comprise third party apps delivering content to Android users, such as e-books and music.

${ }^{73}$ Apart from positive indirect network effects, there might be also negative indirect network effects between at least two sides of the business, namely between the "advertisers group" and the "Android users group". Arguably, the fact that there are more members from the advertisers group could eventually decrease the value of the platform to the Android users, for example through reduced data protection and more intrusive targeted advertising based on users' revealed interests.
} 
advertising and in-app advertising, from application providers who sell their products to Android users via Google Play, and from directly selling content and services to mobile users. Instead, on other sides of the platform, Google most likely loses money, in particular by subsidising the production and sale of comparatively affordable mobile devices through the free (i.e. at no charge) availability of its operating system to handset manufacturers. Moreover, Google subsidises application developers by making available tools that help them write applications, and providing other forms of assistance making it easier for developers to write applications for the Android platform.

From an economic perspective, fragmentation could be viewed as a manifestation of "negative externalities". Typically, economic agents want to be able to find complementary products for the platform they use. Computer users and video game users want to find software (applications) and videogames respectively. Conversely, software developers and videogame makers want to focus their efforts on platforms that will demand their respective products. Each side values having the other side on board. Moreover, each side benefits the more users there are on the other side. In this context, the software platform is the set of institutional arrangements upon which the transaction (e.g. buying a software application that runs on a device) takes place. Arguably, the software platform succeeds if it can envisage a pricing structure and other mechanisms that internalise the externalities between the two or more sides. In this respect, the economic literature on two-sided markets views software platforms as "demandcoordinators". The software platform create value "out of thin air", in the sense that the value in question could not have been created without bringing these different customer groups together. In this respect, searching for the most suitable governance structure becomes an essential in building a successful software business. ${ }^{74}$

The key to unlocking the potential value of interactions between different customer groups lies in the platform's ability to reduce or eliminate costs of search, matching and negotiation that would otherwise impede such interactions. Arguably, the value of a platform to its owner, and to

\footnotetext{
${ }^{74}$ David S. Evans, Platform Economics: Essays on Multi-Sided Businesses (Boston: Competition Policy International, 2001), 92 ("Computer operating system characteristics are similar to those we have seen in our review of other two-sided markets. The business is about the search for the right price structure that will get both sides on board").
} 
the different member groups, does not only depend on the extent to which the owner can generate positive externalities but also limit negative ones. ${ }^{75}$

For software platform owners, fragmentation raises serious concerns over indirect negative externalities: members of one group become generally less attractive and this discourages members from another group. Put differently, fragmentation reduces the number of members that can interact with each other. If hardware makers fork the platform, app developers could be negatively affected because they might need to write multiple versions of the same application to make sure that the application works the same way for all users of the various fragmented versions of the platform. Incompatibilities due to hardware differentiation can drive application developers away from the platform. Writing software applications has fixed costs. Developers may decide not to write for the software platform if they cannot reach enough users with a single version of their applications. This in turn makes the platform less attractive to users, and ultimately this is likely to harm hardware sales. Weak governance rules applied to groups of users (handset manufacturers, app developers) would likely result in more fragmentation and other problems that make the platform less attractive to other groups of users. Due to under-adoption, the platform would then risk collapsing.

'Platform economics' would thus suggest that in order to deal with externalities among members of different user groups, platforms adopt governance systems made of binding standards (e.g., formats for interactions like Twitter's 280-character statement) and rules (requirements or prohibitions) ${ }^{76}$ While the early economic literature on multisided markets focused on pricing as the platform's most prominent governance tool, subsequent research contributions on platforms highlight a broader regulatory role exercised by multisided platforms. Not only do platforms decide on the price structure, but they make extensive use of contracts with members of the different platform groups, decide on the technological design of the system, resort to various informational tools, etc. ${ }^{77}$

\footnotetext{
${ }^{75}$ David S. Evans, "Governing bad behaviour by users of multi-sided platforms", Berkeley Technology Law Journal 2, no. 7 (2012): 1235.

${ }^{76}$ Evans, "Governing Bad Behaviour", 1243.

${ }^{77}$ See Kevin J. Boudreau and Andrei Hagiu, "Platform rules: Multi-sided platforms as regulators", in Platforms, Markets and Innovation, ed. Annabelle Gawer (Cheltenham: Edward Elgar Publishing, 2009).
} 
From the perspective of the economics of two-sided markets, many of the standards and rules enforced by platform owners could promote positive externalities and reduce negative ones. With regard to the Android platform, for instance, Google has not only encouraged more participation through a suitable price structure and support of specific groups (e.g. free operating system to device manufacturers; free of charge tools for app developers, etc.) but has reduced transaction costs between Android users and app developers by creating an app store, the Google Play. Moreover, as we have seen in Section 2 of this article, Android's governance system requires members of different groups to use compatible hardware and software technologies. Standards and rules work together to create a platform in which mobile devices can work with applications and applications can work with hardware so long as both sides comply with the standards. Negative externalities are reduced by preventing hardware makers and application developers from doing certain things that would prevent their respective parts of the platform from working together, leading also to a poor user experience. ${ }^{78}$

It follows that when the platform owner tries to reduce negative externalities like fragmentation, the assumption should be that what it does is also in the interest of the other multiple platform participants. The platform orchestrator could impose restraints on members on one side of the platform that would not seem to benefit them. However, those requirements could benefit a group of members on the other side of the platform. If the demand of the latter group of customers increases, this could in turn enhance the value of the platform also to the benefit of the first group, on which the requirement was imposed despite their reservations. The platform owner in pursuing its own interests will adopt rules and standards that reduce negative externalities and increase positive externalities. The welfare of the platform participants is increased as well as the platform orchestrator's profits. ${ }^{79}$

While not denying that platforms' standards and rules could at times serve as tools to foreclose competition, the economics of two-sided markets provides strong support for a presumption ("screen") in competition law that platform governance systems are efficient and procompetitive.

\footnotetext{
${ }^{78}$ See Yoo, "Open source, modular platforms", ("permitting device manufacturers to sell both CDD-compliant and CDD-noncompliant Android phones can... create potential confusion among consumers over which phones are Android compliant and which ones are not"), 34 .

${ }^{79}$ Davis S. Evans, "The antitrust analysis of rules and standards for software platforms", University of Chicago Coase-Sandor Institute for Law \& Economics Research Paper No. 708 (2014): 2.
} 
The competition enforcer or complainant then has the burden of demonstrating that the practice under anti-trust scrutiny does not follow from the application of a software platform's government system aiming at the restriction of negative externalities and the promotion of positive ones. ${ }^{80}$

\subsection{A more techno-economic approach to fragmentation issues?}

As seen in the previous Subsection, the economics of multisided platforms would seem to suggest that most of the practices engaged in by Google as the orchestrator of the Android platform should be considered as efficient or procompetitive efforts to harness externalities for the platform. Google's governance system is composed of standards and rules aimed at maximising the potential of direct and indirect network effects. ${ }^{81}$ Thus, since fragmentation causes negative indirect network effects, it can be assumed that standards and rules which prevent fragmentation are efficient and, ultimately, procompetitive, in the sense that they promote interplatform competition, e.g. between Android and other mobile platforms such as Apple's iPhone.

Without the benefit of the Decision, it is not possible to know whether the theoretical discussions briefly sketched above played any significant role in the Commission's assessment of Google's practices. Reading the Press Release, one would gain the impression that the Commission has embraced a rather pragmatic approach and discarded broad fragmentation "red herrings".

Notwithstanding, there are important theoretical reasons that encourage a critical assessment of the fragmentation defence by dominant undertakings under Article 102 TFEU in the specific case of the Android platform. One of the reasons is that the "transactional view" at the core of the now dominant economic theory on platforms could be at odds with a more "technological view" of platforms. The latter, however, would appear more suitable to the competition policy assessment of innovation ecosystems like the Android mobile platform. ${ }^{82}$

\footnotetext{
${ }^{80}$ Evans, "The antitrust analysis", 34.

${ }^{81}$ This also implies, however, that Android has to balance the privacy of Android users against the monetisation interests of app developers and advertisers. Android's weak data protection policies and enforcement of platform data-related rules vis-à-vis app developers reflect the business reality that most of Google's revenues come from these two groups of users.

${ }^{82}$ See Simonetta Vezzoso, "Open digital platforms and antitrust: Towards a more techno-economic approach", in Recht und Ökonomie, ed. Oliver Budzinski and Justis Haucap (forthcoming: Nomos, 2018).
} 
Putting it rather bluntly, it might be too simplistic to assume that, as argued by the economics of two-sided markets, the main modality of interactions on the Android platform is a mere transactional relationship like in a heterosexual dating club. Android is first and foremost a technological platform, i.e. the result of purposeful organizational design for harnessing third parties' modular contributions (new apps, innovative handsets). ${ }^{83}$ The platform grows and flourishes thanks to those collaborative innovators. The technological platform ensures some sort of federation of the different complementors' groups (handset manufacturers, app developers) into a collective so that coordination among agents can happen. Competition and innovation shape the way technological platforms evolve.

Arguably, Android has the nature of a modular ecosystem allowing independent firms like apps developers and handset manufacturers to introduce innovations into an established environment and conduct independent experimentation. Android's open architecture encourages innovation at different layers, thus in principle spurring market entry. The Android platform is open to handset manufacturers, which can use the platform's core technology, i.e. the operating system, free of charge. By releasing the operating system by way of open source licences, Google has opened the mobile market, which was initially characterised by a number of closed ecosystems.$^{84}$ Entry on the handset and app markets is encouraged insofar as the entrant can make use of the interfaces already in place and produce its system compatible complement. ${ }^{85}$ As seen above, Android's licensing arrangements enable hardware makers to modify the code for the software platform. The open source model encourages innovation by allowing anyone to introduce changes. Those changes, in the case of handset manufacturers, can be made proprietary. i.e. not subject to copyleft provisions.

\footnotetext{
83 "The most important part of open source is that people are allowed to do what they are good at", Linus Torvalds in Sam Machkovech, "Linus Torvalds on why he isn't nice: 'I don't care about you", Ars technica, January 15, 2015, http://arstechnica.com/business/2015/01/linus-torvalds-on-whyhe-isnt-nice-i-dont-care-about-you/.

${ }^{84} \mathrm{~A}$ more drastic move for Google could have been to forfeit its operating system to a non-profit organization. In this way, the orchestrator still retains technological control while credibly committing against exploiting locked-in users.

${ }^{85}$ Another type of opening vis à vis handset manufacturers is when the system owner charges licensing fees in exchange for the mobile operating system, such as in the case of Microsoft Phone. Relative to a situation of complete closure of a system, opening the system imposing licensing fees creates more diversity of the components available on the system.
} 
Furthermore, Android is open at the software or app layer. Thanks to open and well documented application programming interfaces (APIs), and other development tools, app developers create applications which can be sold and distributed through Google Play application store (and third-party stores). Through APIs, developers can also access user data. Importantly, through interfaces the platform owner can have access to external capabilities and distributed heterogeneous knowledge and derive value from platform's complementary innovations.

In this light, some innovations by users on one side of the platform can be perceived by Google as a danger and a challenge to its platform's control, as in the case of Acer's intention to launch the Aliyun OS fork mentioned above. More appropriately, however, these internal tensions are the logical consequence of having forfeited technologies to harness third parties' innovative contributions thanks to which Android in very short time could become the dominant mobile platform. While Google's continuous incentives to sponsor and innovate keep the platform alive, a truly multisided assessment of the practices engaged by the platform sponsor would also include the careful assessment of the effects of the platform orchestrator's practices on the innovation incentives of the separate groups of platform users.

Moreover, the competition policy assessment of these practices should duly consider that forks of Android AOSP can actually promote consumer welfare, something that the economics of two-sided platforms instead tends to disregard. The basic reason is that these "incompatible" forks increase the variety of handset devices and make them available to consumers, i.e. users on another side of the platform, who might have diverse preferences and needs that are only partially fulfilled by Android-compatible mobile operating systems. For instance, a sizeable number of consumers would arguably favour a more privacy-respecting, less intrusive, ${ }^{86}$ and still reasonably priced mobile device. ${ }^{87}$

\footnotetext{
${ }^{86}$ BBC News, "Google admits changing phone settings remotely", BBC News, September 17, 2018, https://www.bbc.com/news/technology-45546276.

${ }^{87}$ Margrethe Vestager, "Getting the best out of technology", Speech delivered at CEPS Corporate Breakfast, September 10, 2018, https://ec.europa.eu/commission/commissioners/2014-2019/ vestager/announcements/getting-best-out-technology_en ("The thing about open-source software is that anyone can adapt it, to create new versions of the software - known in the jargon as "forks". That's great news for consumers. Because it means there's room for different operating systems to compete, all based on Android, but with new features that consumers might prefer").
} 
As reminded by Competition Commissioner Margrethe Vestager in a recent speech referring to the Android Decision, "[W]hat matters is whether there's room for innovation. Whether technology's potential is actually used. Or whether that potential gets lost - not because of any problems with the technology itself, but because some companies decided it was in their commercial interests to hold back innovation". ${ }^{88}$

\section{Conclusion}

The Android Decision already went down in the EU competition enforcement history because of its record fine of $€ 4.3$ billion. Based on the limited public information available, as the Decision has not yet been published, the article proposes some first reflections on the forking restrictions that Google imposed on handset manufacturers. The European Commission considers these restrictions in breach of Article 102 TFEU, alongside tying and exclusivity practices. Moreover, the Commission excludes that the forking restrictions could be justified by fragmentation concerns. The article describes a possible reasoning underpinning Google's fragmentation argument based on the economics of two-sided platforms. This justification stems from a purely "transactional view" of platforms. The article concludes that this view is only partially suitable to provide an accurate description of complex innovation ecosystems for the purposes of competition policy enforcement.

\section{Bibliography}

Akmar, Pinar. "Will the European Commission's Google Android Decision Benefit Consumers?". Truth on the Market. July 19, 2018. https://truthonthemarket. com/2018/07/19/will-the-european-commissions-google-android-decision-benefitconsumers/amp.

Auer, Dick and Nicolas Petit. "Two-Sided Markets and the Challenge of Turning Economic Theory into Antitrust Policy”. Antitrust Bulletin 60, no.4 (2015): 426-461.

BBC News. "Google admits changing phone settings remotely". BBC News. September 17, 2018. https://www.bbc.com/news/technology-45546276.

Bergen, Mark. "Alphabet Soars to Record After Earnings Wallop Expectations". Bloomberg. July 24, 2018. https://www.bloomberg.com/news/articles/2018-07-24/ alphabet-results-support-company-confidence-in-face-of-eu-curbs.

${ }^{88}$ Vestager, "Getting the best out of technology". 
Bergen, Mark. "Microsoft Quietly Retreats from FairSearch, Watchdog Behind Google Antitrust Cases”. Recode. January22,2016.https://www.recode.net/2016/1/22/11588992/ microsoft-quietly-retreats-from-fairsearch-watchdog-behind-google.

Boudreau, Kevin J. and Andrei Hagiu. "Platform Rules: Multi-Sided Platforms as Regulators". In Platforms, Markets and Innovation, edited by Annabelle Gawer, 163191. Cheltenham: Edward Elgar Publishing, 2009.

Bray, Tim. "On Android Compatibility”. Android Developers Blog. May 31, 2010. https:// android-developers.googleblog.com/2010/05/on-android-compatibility.html

Colomo, Pablo Ibanez. "The Android decision is out: the exciting legal stuff beneath the noise”. Chilling Competition. July 18, 2018. https://chillingcompetition.com/2018/07/18/ the-android-decision-is-out-the-exciting-legal-stuff-beneath-the-noise-by-pablo/amp/.

Commission Decision of 27 June 2017, relating to proceedings under Article 102 of the Treaty on the Functioning of the European Union and Article 54 of the Agreement on the European Economic Area - CASE AT.39740 Google Search (Shopping), http:// ec.europa.eu/competition/antitrust/cases/dec_docs/39740/39740_14996_3.pdf.

Complaint of Disconnect, Inc. “Regarding Google's infringement of Article 102 TFEU through bundling into the Android platform and the related exclusion of competing privacy and security technology - Case COMP/40099", June 2015, https://www.documentcloud.org/documents/2109044-disconnect-google-antitrust-complaint.html

Cornière, Alexandre de, and Greg Taylor. "On the economics of the Google Android case”. Vox. August 15, 2018. https://voxeu.org/article/economics-google-android-case.

Economides, Nicholas and Ioannis Lianos. "A Critical Appraisal of Remedies in the E.U. Microsoft Cases”. Columbia Business Law Review no. 2 (2010): 346-420.

Edelman, Benjamin and Damien Geradin. "Android and Competition Law: Exploring and Assessing Google's Practices in Mobile”. European Competition Journal 12 (2016): 159-194

European Commission. “Antitrust: Commission fines Google €4.34 billion for illegal practices regarding Android mobile devices to strengthen dominance of Google's search engine”. EC Press Release. July 18, 2018. http://europa.eu/rapid/press-release _IP-18-4581_en.htm.

European Commission. "Antitrust: Commission opens formal investigation against Google in relation to Android mobile operating system". EU Press Release, April 15, 2015. http://europa.eu/rapid/press-release_MEMO-15-4782_en.htm

European Commission. "Commission takes further steps in investigations alleging Google's comparison shopping and advertising-related practices breach EU rules”. EC Press Release. July 14, 2016. http://europa.eu/rapid/press-release_IP-16-2532_en.htm.

European Commission. "Statement by Commissioner Vestager on Commission decision to fine Google $€ 4.34$ billion for illegal practices regarding Android mobile devices 
to strengthen dominance of Google's search engine”. July 18, 2018, http://europa.eu/ rapid/press-release_STATEMENT-18-4584_en.htm.

Evans, David S. "Governing bad behaviour by users of multi-sided platforms". Berkeley Technology Law Journal 2, no. 7 (2012): 1201-1250.

Evans, David S. "The antitrust analysis of rules and standards for software platforms". University of Chicago Coase-Sandor Institute for Law \& Economics Research Paper No. 708 (2014): 1-38.

Evans, David S. Platform Economics: Essays on Multi-Sided Businesses. Boston: Competition Policy International, 2001.

FairSearch. "FairSearch announces complaint in EU on Google's anti-competitive mobile strategy". April 8, 2013. http://fairsearch.org/fairsearch-announces-complaint-in-eu-on-googles-anti-competitive-mobile-strategy/.

Federal Antimonopoly Service of the Russian Federation. "FAS Russia reaches settlement with Google”. FAS Press Release. April 17, 2017. http://en.fas.gov.ru/press-center/ news/detail.html?id=49774.

Gal, Michal S. and Daniel L. Rubinfeld. "The hidden costs of free goods: Implications for antitrust enforcement”. Antitrust Law Journal 80, no.401 (2016): 521-562.

Gawer, Annabelle and Michael A. Cusumano. "Platform leadership". Harvard Business School Pres. June 24, 2002. https://hbswk.hbs.edu/archive/platform-leadershiphow-intel-microsoft-and-cisco-drive-industry-innovation-do-you-have-platformleadership.

Hildenbrand, Jerry. "Acer forced to halt device launch over Android compliance here's why". Android Central. September 14, 2012. https://www.androidcentral.com/ acer-forced-halt-device-launch-over-android-compliance-here-s-why.

Houck, Stephen. “Android - is there a viable monopolization case?”. August 1, 2018. https://papers.ssrn.com/sol3/papers.cfm?abstract_id=3230355.

Jansen, Slinger and Michael A. Cusumano. "Defining software ecosystems: a survey of software platforms and business network governance". In Software Ecosystems: Analyzing and Managing Business Networks in the Software Industry, edited by Slinger Jansen, Sjaak Brinkkemper and Michael Cusumano, 13-28. Cheltenham: Edward Elgar Publishing, 2013.

Karhu, Kimmo, Robin Gustafsson, and Kalle Lyytinen. "Exploiting and defending open digital platforms with boundary resources: Android's five platform forks". Information Systems Research 29, no. 2(2018): 479-487.

Kiselyova, Maria. "Russia’s Yandex says complained to EU over Google's Android”. Reuters. November 13, 2015. https://www.reuters.com/article/us-eu-antitrust-googleyandex-idUSKCN0T21L420151113. 
Körber, Torsten. "Let's talk about Android - Observations on competition in the field of mobile operating systems". Working Paper (2014). http://papers.ssrn.com/sol3/papers. cfm?abstract_id=2462393.

Levy, Steven. In the Plex: How Google Thinks, Works, and Shapes Our Lives. New York: Simon and Schuster, 2011.

Machkovech, Sam. “Linus Torvalds on why he isn't nice: 'I don't care about you'”. Ars technical. January 15, 2015. http://arstechnica.com/business/2015/01/linus-torvalds-onwhy-he-isnt-nice-i-dont-care-about-you/.

Maurer, Stephen M. “The Penguin and the cartel: Rethinking antitrust and innovation policy for the age of commercial open source”. Utah Law Review 1 (2012): 269-318.

McGonigle, Brenden. "How the Russian search market looks now". Search Engine Land. September 25, 2017. https://searchengineland.com/how-russian-search-market-looks283072/amp.

Newman, John M. "Antitrust in zero-price markets: Foundations". University of Pennsylvania Law Review, 164 (2015): 149-2016

Nyman, Linus. "Understanding code forking in open source software". Hanken School of Economics (2015). http://s8.pdfconvertonline.com/convert/p3r68-cdx67/cppml5oyg9.pdf.

Open Handset Alliance. “Overview”. http://www.openhandsetalliance.com/oha_overview.html.

Parker, Geoffrey G., Marshall W. Van Alstyne, and Sangeet P. Choudary. Platform Revolution. New York: W.W. Norton \& Company, 2016.

Patel, Nilay. "How Google controls Android: digging deep into the Skyhook filings". The Verge. May 12, 2011. https://www.theverge.com/2011/05/12/google-android-skyhooklawsuit-motorola-samsung.

Pichai, Sundar. "Android has created more choice, not less". Google Blog. July 18, 2018. https://www.blog.google/around-the-globe/google-europe/android-has-createdmore-choice-not-less/.

Picker, Randy. "The European Commission picks a fight with Google Android over business models". Pro Market. July 23, 2018. https://promarket.org/europeancommission-picks-fight-google-android-business-models/.

Reuters. "Google foe takes Android complaint to EU regulators”. Fortune. March 7, 2017. http://fortune.com/2017/03/07/google-antitrust-eu-android/.

Schmidt, Douglas. "Google data collection”. Digital Content Next. August 2018. https:// digitalcontentnext.org/wp-content/uploads/2018/08/DCN-Google-Data-CollectionPaper.pdf.

Sidak, J. Gregory. “Do free mobile apps harm consumers?”. Working Paper (2014). http:// papers.ssrn.com/sol3/papers.cfm?abstract_id=2507905. 
Simcoe, Timothy and Jeremy Watson. "Forking, fragmentation, and splintering". Working Paper - Boston University (2017).

Sullivan, Danny. "Google: Acer can't work on 'non-compatible android' \& be part of Open Handset Alliance". Marketing Land. September 14, 2012. https://marketingland.com/google-acer-android-aliyun-21631.

Transcript of Eric Schmidt's testimony at the Oracle v. Google trial, http://www.groklaw. net/articlebasic.php?story=20120424115304346.

Trezentos, Paulo. "Enough is enough: When Google evil reaches Android app stores". Aptoide. June 17, 2014. https://blog.aptoide.com/enough_is_enough_when_google_ evil_reaches_android_app_stores-2/.

Vestager, Margrethe. "Getting the best out of technology". Speech delivered at CEPS Corporate Breakfast. September 10, 2018. https:/ec.europa.eu/commission/ commissioners/2014-2019/vestager/announcements/getting-best-out-technology_en

Vezzoso, Simonetta. "Open digital platforms and antitrust: Towards a more technoeconomic approach". In Recht und Ökonomie, edited by Oliver Budzinski and Justis Haucap. Forthcoming: Nomos, 2018.

Vezzoso, Simonetta. "Open source and merger policy - Insights from the European Commission's Oracle/Sun Decision”. International Review of Intellectual and Competition Law 1 (2011): 344-361.

Vogelstein, Fred. Dogfight: How Apple and Google Went to War and Started a Revolution. New York: Harper Collins Publishers, 2013.

Waters, Richard. "Brussels takes aim at Google's mobile strategy". Financial Times. July 18, 2018. https://www.ft.com/content/8ddd8b86-8aa9-11e8-bf9e-8771d5404543.

Wikipedia. "List of Google apps for Android". Wikipedia. http://en.wikipedia.org/wiki/ List_of_Google_apps_for_Android.

White, Aoife, Stephanie Bodoni, and Natalia Drozdiak. "Google fined record \$5 billion by EU, given 90 days to stop 'illegal practices”. Bloomberg. July 18, 2018. https:// www.bloomberg.com/news/articles/2018-07-17/google-said-to-have-11th-hour-callwith-eu-ahead-of-android-fine.

Wielen, Bernd van de. "Insights into the 2.3 billion Android smartphones in use around the world". Newzoo. January 17, 2018. https://newzoo.com/insights/articles/ insights-into-the-2-3-billion-android-smartphones-in-use-around-the-world/.

Yang, Yuan. "Why millennials are driving cashless revolution in China". Financial Times. July 17, 2018. https://www.ft.com/content/539e39b8-851b-11e8-a29d-73e3d454535d.

Yoo, Christopher S. "Open source, modular platforms, and the challenge of fragmentation". University of Pennsylvania, Institute for Law \& Economic Research Paper No. 16-29 (2016). https://papers.ssrn.com/sol3/papers.cfm?abstract_id=2866666. 